\title{
Room Temperature Magnetocaloric Effect in
}

\section{$\mathrm{Mn}_{1.25} \mathrm{Fe}_{1.75} \mathrm{Ga}$ Heusler Alloys}

Ahmed A. El-Gendy ${ }^{* 1,2}$, George C. Hadjipanayis ${ }^{* 1}$

${ }^{1}$ Department of Physics and Astronomy, University of Delaware, 217 Sharp Lab., Newark, Delaware 19711, USA

${ }^{2}$ Nanotechnology and Nanometrology Lab., National Institute for Standards (NIS), 136 Tersa St., Haram, Giza 12211, Egypt

\section{Abstract}

A room temperature magnetocaloric material with composition $\mathrm{Mn}_{1.25} \mathrm{Fe}_{1.75} \mathrm{Ga}$ is reported in this paper. The as-synthesized melt-spun ribbons have the pure $\mathrm{L} 2{ }_{1}$ cubic structure and a homogeneous microstructure with an average grain size of $6 \mu \mathrm{m}$ and show a ferromagnetic to paramagnetic transition at $296 \mathrm{~K}$. The change in entropy determined from the M versus $\mathrm{H}$ curves was found to be $3 \mathrm{Jkg}^{-1} \mathrm{~K}^{-1}$ at $296 \mathrm{~K}$ and $3 \mathrm{~T}$, which is good in comparison with the values of commonly used materials for magnetic refrigeration. However, in comparison with other materials, the room temperature magnetocaloric effect is obtained by tuning the composition of the parent alloy without the need of another heat treatment. This important result opens opportunities for magnetic refrigeration near room temperature.

(C) 2016. This manuscript version is made available under the Elsevier user license http://www.elsevier.com/open-access/userlicense/1.0/ 
Recently, there is a growing interest for materials with room temperature magnetocaloric behavior for numerous applications such as heat pumps, high-temperature cooling, and, most particularly, heat conversion. ${ }^{1-18}$ Magnetocaloric heat conversion systems aim at transforming heat into mechanical or electrical energy. The intense research activity over the past fifteen years on room-temperature magnetic refrigeration has led to the discovery of numerous performing magnetocaloric materials with working temperature around $300 \mathrm{~K}$. Previous studies have shown that the Ni-Mn-Ga alloys are common candidates as magnetic refrigerant materials. In these materials the transition temperature $\mathrm{T}_{\mathrm{C}}$ can be tuned to be near room temperature ${ }^{6-13}$ by adjusting the Ni:Mn ratio, adding another element such as In, and annealing at high temperatures for long time $^{19-21}$. In earlier work in 1997, it was reported by Gschneidner et.al. ${ }^{3}$ that the entropy change of $\mathrm{Gd}_{5} \mathrm{Si}_{2} \mathrm{Ge}_{2}$ with a fist order phase transition is about $18 \mathrm{~J} / \mathrm{kgK}$ near its Curie temperature $\mathrm{T}_{\mathrm{C}}=278$ $\mathrm{K}$ for a field change of $0-5 \mathrm{~T}$. Du et.al. ${ }^{22}$ observed that $\mathrm{La}_{1-\mathrm{x}} \mathrm{Ca}_{\mathrm{x}} \mathrm{MnO}_{3}(\mathrm{x}=0.2)$ has a large entropy change of $5.5 \mathrm{~J} / \mathrm{kgK}$ at $230 \mathrm{~K}$ for a field change of $0-1.5 \mathrm{~T}$. Subsequently, some magnetocaloric materials with a first-order magnetic transition such as $\mathrm{LaFe}_{13-\mathrm{x}} \mathrm{Si}_{\mathrm{x}}{ }^{4,23}, \mathrm{MnAs}_{1-\mathrm{x}} \mathrm{Sb}_{\mathrm{x}}{ }^{24}$, and $\mathrm{MnFeP}_{0.45} \mathrm{As}_{0.55}{ }^{5}$ were reported. These findings have caused a wave of MCE (is this defined) research for the investigation of less expensive, and more robust magnetocaloric materials with working temperature near ambient temperature.

Herein, we report the synthesis of an as-made $\mathrm{Mn}_{1.25} \mathrm{Fe}_{1.75} \mathrm{Ga}$ Heusler alloy with optimized composition that shows a magnetostructural transition (ferromagnetic to paramagnetic transition) near room temperature. The corresponding amounts of high-purity metals (iron, manganese, and gallium) were arc-melted under a 10 mbar of argon atmosphere. The resulting polycrystalline ingot was melt-spun with a wheel speed of $30 \mathrm{~m} / \mathrm{s}$ to obtain ribbons with a fine microstructure with an average grain size of 5 to $7 \mu \mathrm{m}$ as shown in the scanning electron microscope images in Figure 
1(a). The morphology of the sample shows the formation of equiaxed (hexagonal or pentagonal shape) grains. The exact composition was confirmed using energy dispersive x-ray (EDX) analysis. The microstructure of a cross sectioned sample has been studied to reveal a smooth and columnar-type microstructure (Figure 1(b)). The room-temperature crystal structure was characterized by X-ray diffraction (XRD) with $\mathrm{Cu}$ Ka radiation. The XRD patterns show that the as-made ribbons have the $\mathrm{L}_{21}$ cubic structure (Figure 2) which is a typical structure for Heusler alloys $^{19-21}$.

In order to investigate the magnetocaloric properties of the synthesized samples, the dependence of magnetization on external magnetic field up to $3 \mathrm{~T}$ was measured. Fig. 3(a) shows the isothermal magnetization curves $(\mathrm{M}-\mathrm{H})$ measured at different temperatures in the range of 60 to $390 \mathrm{~K}$. The curves are measured on heating the sample with a temperature interval of $5 \mathrm{~K}$. The change in magnetic entropy $\left(\Delta \mathrm{S}_{\mathrm{M}}\right)$ and the relative cooling power or refrigeration capacity $(\mathrm{RCP})$ are important parameters in quantifying the magnetocaloric effect. Based on the measured isothermal magnetization curves of $\mathrm{Mn}_{1.25} \mathrm{Fe}_{1.75} \mathrm{Ga}$ alloy, the $\Delta \mathrm{S}_{\mathrm{M}}$ values were obtained numerically from the Maxwell relation ${ }^{14-16}$. The $\Delta \mathrm{S}_{\mathrm{M}}$ values estimated at different temperatures in a magnetic field of $0.1,0.5,1,2$, and $3 \mathrm{~T}$ for $\mathrm{Mn}_{1.25} \mathrm{Fe}_{1.75} \mathrm{Ga}$ alloy are shown in Fig. 3(b); the highest value of $\Delta \mathrm{S}_{\mathrm{M}}$ is $3.0 \mathrm{~J} / \mathrm{Kg}^{-1} \mathrm{~K}^{-1}$ at $296 \mathrm{~K}$ and $3 \mathrm{~T}$ applied field. The RCP can be determined from the change in entropy with temperature by multiplying the maximum change in entropy $\left(\Delta \mathrm{S}_{\mathrm{M}}\right)_{\max }$ with the full width at half maximum ( $\left.\delta \mathrm{T}_{\mathrm{FWHM}}\right)$ of the $\Delta \mathrm{S}_{\mathrm{M}}(\mathrm{T}) \mathrm{T}$ curve $\mathrm{e}^{25}$. Such calculations yield RCP values of $0.3,6.8,20,59,106 \mathrm{~J} / \mathrm{kg}$ for $\Delta \mathrm{S}_{\mathrm{M}}$ measured at $0.1,0.5,1,2,3 \mathrm{~T}$, respectively. These values are comparable to those reported in other materials ${ }^{13-16}$.

From the isothermal M-H curves shown in (Fig. 3(a)) the magnetization is found to increase and then decrease with increasing temperature indicating the presence of magnetostructural transition 
below $275 \mathrm{~K}$. This is further confirmed by the temperature dependence of a.c. susceptibility measurements (Fig. 4) which suggest two transition temperatures at $225 \mathrm{~K}$ ( $\mathrm{T}_{\mathrm{C} 1}$ (ferri to ferro)) and at $300 \mathrm{~K}$ ( $\mathrm{T}_{\mathrm{C} 2}$ (ferro to para)). Another evidence for the ferro to ferrimagnetic transition is the temperature dependence of $\mathrm{M}$ at $3 \mathrm{~T}$ which showed a drastic decrease below $275 \mathrm{~K}$ (Fig. 4).

To understand further the magnetostructural transitions in $\mathrm{Mn}_{1.25} \mathrm{Fe}_{1.75} \mathrm{Ga}$ alloy, the temperature dependence of magnetization was measured at different fields of $0.1,1,10,20$, and $30 \mathrm{kOe}$ (Figure 4) in the temperature range of 50-390 K. In the M-T curve at $100 \mathrm{Oe}$, the heating and cooling curves are essentially coincident from $50 \mathrm{~K}$ to $275 \mathrm{~K}$. On heating, a rapid increase in magnetization with temperature is observed from $275 \mathrm{~K}$ to $305 \mathrm{~K}$, followed by a rapid decrease in the temperature range from $306 \mathrm{~K}$ to $350 \mathrm{~K}$ (Figure 5(a)). On cooling, the same behavior was observed as with heating with the only difference in the magnetization values. The observed hysteresis at lower temperature in Fig. 5 reveals a chemical disorder in the Heuslar structure due to the presence of mixed structures of $\mathrm{L} 2_{1}$ as the major phase and $\mathrm{B} 2$ as the minor phase.

The difference in magnetization values on heating and cooling is due to thermal hysteresis. The characteristics of the other plots at 1, 10, 20 and $30 \mathrm{kOe}$ are slightly different from the 100 Oe. Figure 5(b) shows the heating plots at different applied fields. As the field increases, the peak of magnetization occurs at lower temperatures. The Curie temperature is also shifted by changing the applied magnetic field. According to this figure, the magnetization peak and the Curie temperature are shifted from $314 \mathrm{~K}$ at $100 \mathrm{Oe}$ to $280 \mathrm{~K}$ at $3 \mathrm{~T}$ (Fig. 5 (b)).

Generally, in typical Heusler alloys the $\delta \mathrm{M} / \delta \mathrm{T}$ curves which are determined by differentiation of M-T curves are used to study systems with mixed magnetic states ${ }^{21}$ (Fig. 6(a)). The data on this alloy are consistent with those of Ref [20], in which two peaks were observed in 
these curves; a positive peak which represents the first mixed state (ferrimagnetic to ferromagnetic) and a negative peak (ferromagnetic to paramagnetic) which represents the second mixed state. From Figure 6(a), as the applied field is increased from 0.1 to $10 \mathrm{kOe}$, the intensity of the positive peak increases and then decreases when the applied field increases from 10 to $30 \mathrm{kOe}$. In typical Heusler alloys ${ }^{20}$, the $\delta \mathrm{M} / \delta \mathrm{T}$ curves can be related with two transition temperatures, a ferri- to ferromagnetic (the positive maximum of $\delta \mathrm{M} / \delta \mathrm{T}$ ) and a ferro to paramagnetic (Curie temperature) (Figure 6(b)). As shown in Fig. 6(a), a large shift in the ferri- to ferromagnetic transformation was observed by variation of the applied magnetic field. The shift was calculated as a function of the applied field as shown in Fig. 6(c). By applying a larger field the shift was increased from $6 \mathrm{~K}$ at $0.1 \mathrm{~T}$ to $108 \mathrm{~K}$ at $3 \mathrm{~T}$. This reveals strong dependence of the phase transformation on the external field which is a characteristic feature for the magnetocaloric materials.

In summary, room temperature magnetocaloric properties were obtained in as-made $\mathrm{Mn}_{1.25} \mathrm{Fe}_{1.75} \mathrm{Ga}$ ribbons with the $\mathrm{L}_{21}$ structure without the need of high temperature annealing which is common in Heusler alloys. The magnetostructural transition was observed at $296 \mathrm{~K}$ with a change in entropy of $3 \mathrm{Jkg}^{-1} \mathrm{~K}^{-1}$. The a.c. succesptibility $\left(\chi_{\mathrm{ac}}\right)$ measurements reveal two transition temperatures at $225 \mathrm{~K}$ for ferrimagnetic to ferromagnetic and at $300 \mathrm{~K}$ for ferromagnetic to paramagnetic. These findings open routes of using $\mathrm{Mn}_{1.25} \mathrm{Fe}_{1.75} \mathrm{Ga}$ ribbons as potential material for room temperature magnetic refrigeration.

\section{Corresponding Author}

*A.A.E and G.C.H. Corresponding-Authors, E-mail: (algendy@udel.edu, hadii@udel.edu) 


\section{ACKNOWLEDGMENT}

All authors would like to acknowledge support from Department of Energy (DOE) under Award Number DOE-BES-DE-FG02-04ER4612.

Experimental Method:

The room-temperature crystal structure was characterized by X-ray diffraction (XRD) with $\mathrm{Cu} \mathrm{Ka}$ radiation. The magnetic properties were measured using a vibrating sample magnetometer, Quantum Design Versa lab VSM, with magnetic fields up to 3 T. The morphology and elemental analysis of the samples have been obtained using a JEOL 6335F scanning electron microscope (SEM) equipped with an energy-dispersive X-ray (EDS) detector.

\section{References}

[1] A. Biswas, S. Chandra, T. Samanta, M. H. Phan, I. Das, and H. Srikanth, J. Appl. Phys. 113, 17A902 (2013).

[2] Y. Jin, S. Gu, L. H. Bennett, E. Della Torre, V. Provenzano, and Q. Zhao, J. Appl. Phys. 111, 07A950 (2012)

[3] V. K. Pecharsky and K. A. Gschneidner, Phys. Rev. Lett. 78, 4494 (1997).

[4] F. X. Hu, B. G. Shen, J. R. Sun, Z. H. Cheng, G. H. Rao, and X. X. Zhang, Appl. Phys. Lett. 78, 3675 (2001).

[5] O. Tegus, E. Brück, K. H. J. Buschow, and F. R. de Boer, Nature (London) 415, 150 (2002). 
[6] A. Fujita, S. Fujieda, Y. Hasegawa, and K. Fukamichi, Phys. Rev. B 67, 104416 (2003).

[7] K. Mandal, D. Pal, O. Gutfleisch, P. Kerschl, and K.-H. Müller, J. Appl. Phys. 102, 053906 (2007).

[8] V. V. Khovaylo, V. D. Buchelnikov, R. Kainuma, V. V. Koledov, M. Ohtsuka, V. G. Shavrov, T. Takagi, S. V. Taskaev, and A. N. Vasiliev, Phys. Rev. B 72, 224408 (2005).

[9] V. V. Khovaylo, V. Novosad, T. Takagi, D. A. Filippov, R. Z. Levitin, and A. N. Vasil'ev, Phys. Rev. B 70, 174413 (2004).

[10] M. Pasquale, C. P. Sasso, L. H. Lewis, L. Giudici, T. Lograsso, and D. Schlagel, Phys. Rev. $B$ 72, 094435 (2005).

[11] A. K. Giri, B. A. Paterson, M. V. McLeod, C. L. Dennis, B. S. Majumdar, K. C. Cho, and R. D. Shull, J. Appl. Phys. 113, 17A907 (2013).

[12] F. Albertini, F. Canepa, S. Cirafici, E. A. Franceschi, M. Napoletano, A. Paoluzi, L. Pareti, and M. Solzi, J. Magn. Magn. Mater. 272-276, 2111 (2004).

[13] A. Aliev, A. Batdalov, S. Bosko, V. Buchelnikov, I. Dikshtein, V. Khovailo, V. Koledov, R. Levitin, V. Shavrov, and T. Takagi, J. Magn. Magn. Mater. 272-276, 2040 (2004)

[14] A. A. El-Gendy, M. Qian , Z. J. Huba, S. N. Khanna, E. E. Carpenter, Appl. phys. lett. 104, 023111 (2014).

[15] Ahmed A. El-Gendy, George C Hadjipanayis, J. Phys. Chem. C 119(16), 8898 (2015).

[16] A.A. El-Gendy, T. Almuigateeb, E.E. Carpenter, J. Mag. Mag. Mater. 348, 136 (2013).

[17] Ahmed A. El-Gendy, George C Hadjipanayis, J. Phys. D: Appl. Phys. 48 (12), 125001 (2015) 
[18] Ahmed A. El-Gendy, George C Hadjipanayis, IEEE Trans. Magn. 50 (11), 1 (2014)

[19] L. Zhang, J. Wang, H. Hua, C. Jiang, and H. Xu. Appl. Phys. Lett. 105, 112402 (2014)

[20] M. Ovichi, M. Ghahremani, E. D. Torre, L. H. Bennett, F. Johnson, and V. Srivastava, J. Appl. Phys. 115, 17A906 (2014)

[21] K. Mandal, D. Pal, N. Scheerbaum, J. Lyubina, and O. Gutfleisch, J. Appl. Phys. 105, $073509(2009)$

[22] Z. B. Guo, Y. W. Du, J. S. Zhu, H. Huang, W. P. Ding, D. Feng, Phys. Rev. Lett. 78, 1142 (1997)

[23] F. X. Hu, B. G. Shen, J. R. Sun, X. X. Zhang, Chin. Phys. 9, 550 (2000)

[24] H. Wada, Y. Tanabe, Appl. Phys. Lett. 79, 3302 (2001)

[25] A. M. Tishin, Y. I. Spichkin, IOP publishing, (2003), p.p. 406 


\section{Captions}

Figure 1. (a) Surface morphology of melt-spun $\mathrm{Mn}_{1.25} \mathrm{Fe}_{1.75} \mathrm{Ga}$ alloys observed by scanning electron microscopy. (b) Microstructure image of a cross sectioned ribbon.

Figure 2. XRD diffraction patterns of as-made $\mathrm{Mn}_{1.25} \mathrm{Fe}_{1.75} \mathrm{Ga}$ ribbons.

Figure 3. (a) Isothermal magnetization curves $(\mathrm{M}-\mathrm{H})$ measured at temperatures around the magnetostructural transition of $\mathrm{Mn}_{1.25} \mathrm{Fe}_{1.75} \mathrm{Ga}$ ribbons. (b) Temperature dependence of the change in magnetic entropy of $\mathrm{Mn}_{1.25} \mathrm{Fe}_{1.75} \mathrm{Ga}$ ribbons measured with a field of $3 \mathrm{~T}$.

Figure 4. Dependence of A.C. succesptibility $\left(\chi_{\mathrm{ac}}\right)$ on temperature at a field and frequency of 100 Oe and $100 \mathrm{~Hz}$, respectively; also the temperature dependence of $\mathrm{M}$ at $3 \mathrm{~T}$ is shown.

Figure 5. (a) $\mathrm{M}-\mathrm{T}$ curves for $\mathrm{Mn}_{1.25} \mathrm{Fe}_{1.75} \mathrm{Ga}$ at different applied fields for heating and cooling cycles. (b) M-T heating curves show the effect of the applied fields on the transition temperatures.

Figure 6. (a) $\delta \mathrm{M} / \delta \mathrm{T}$ curves in $\mathrm{Mn}_{1.25} \mathrm{Fe}_{1.75} \mathrm{Ga}$ for different applied fields. The data were derived from the isothermal loops in Fig. 5. (b). (b) $\delta \mathrm{M} / \delta \mathrm{T}$ curve at 1000 Oe for understanding the state transitions in $\mathrm{Mn}_{1.25} \mathrm{Fe}_{1.75} \mathrm{Ga}$. (c) The shift of the ferri- to ferromagnetic transformation temperature dependence on the applied magnetic field. 


\section{Figures}
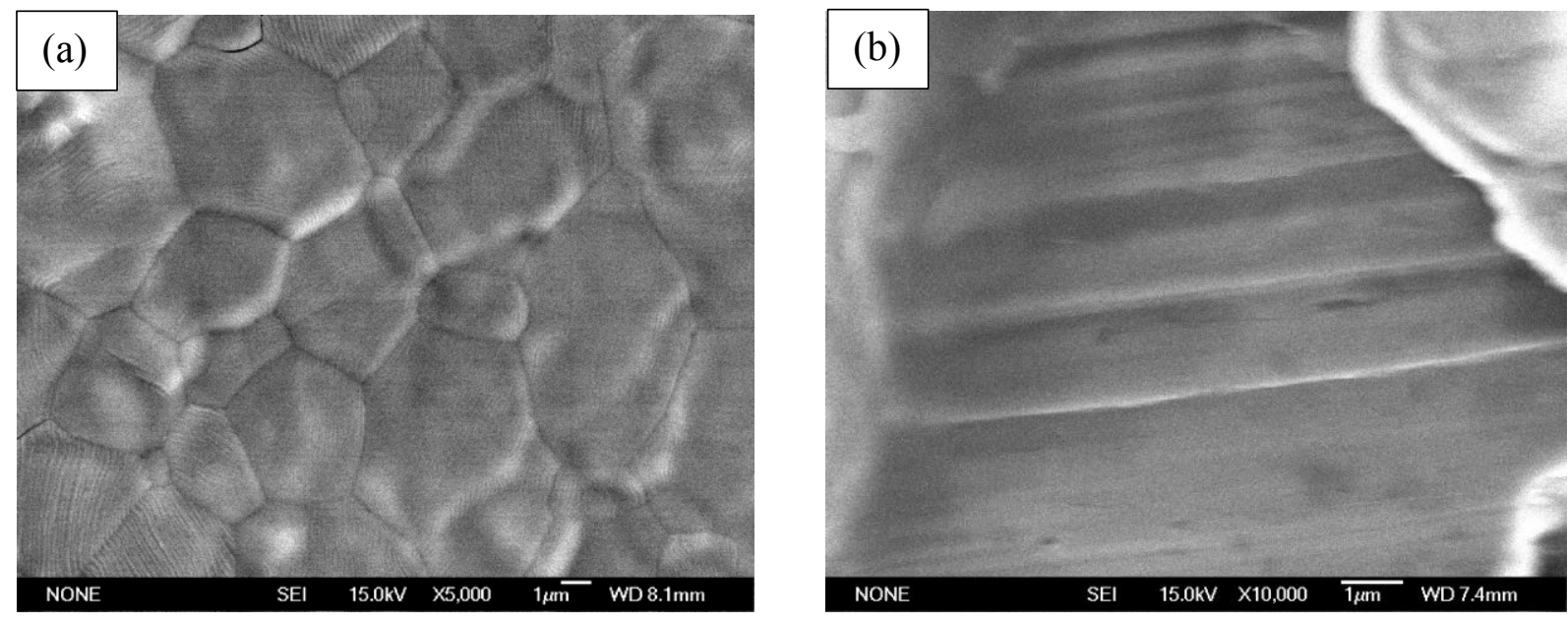

Figure 1. (a) Surface morphology of melt-spun $\mathrm{Mn}_{1.25} \mathrm{Fe}_{1.75} \mathrm{Ga}$ alloys observed by scanning electron microscopy. (b) Microstructure image of a cross sectioned ribbon.

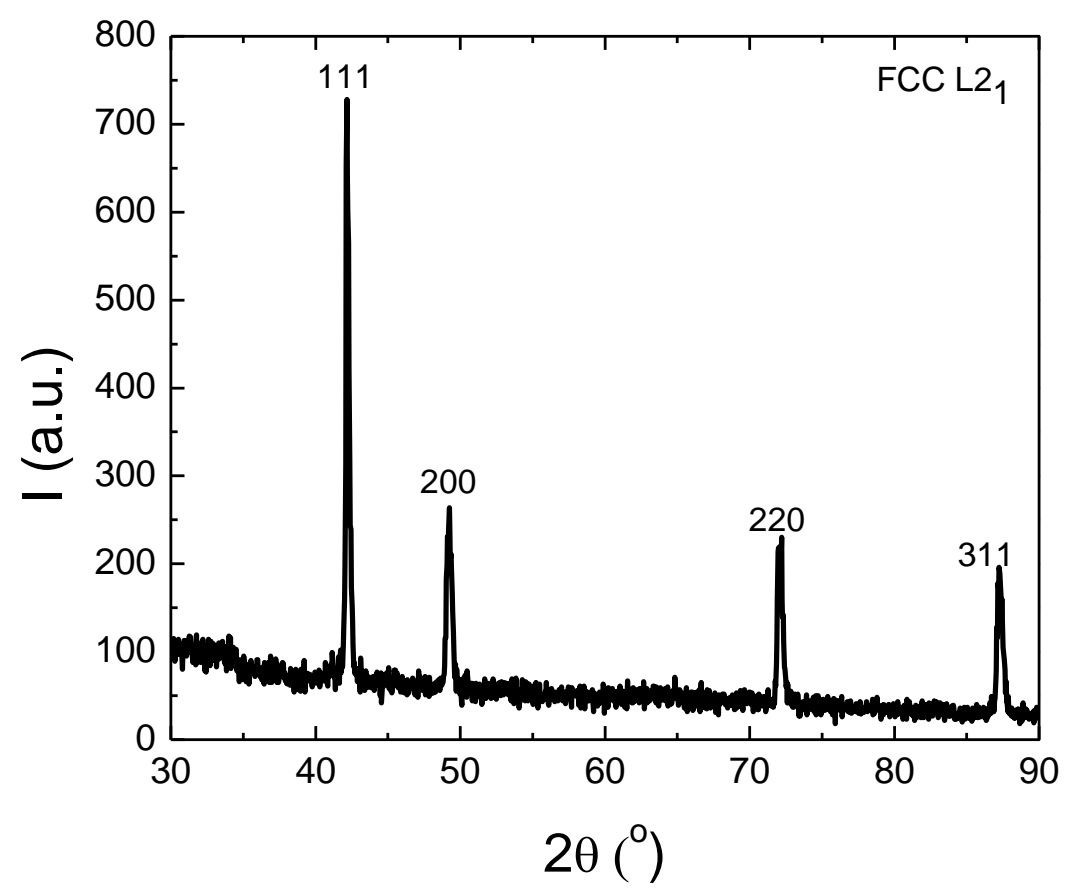

Figure 2. XRD diffraction patterns of as-made $\mathrm{Mn}_{1.25} \mathrm{Fe}_{1.75} \mathrm{Ga}$ ribbons. 

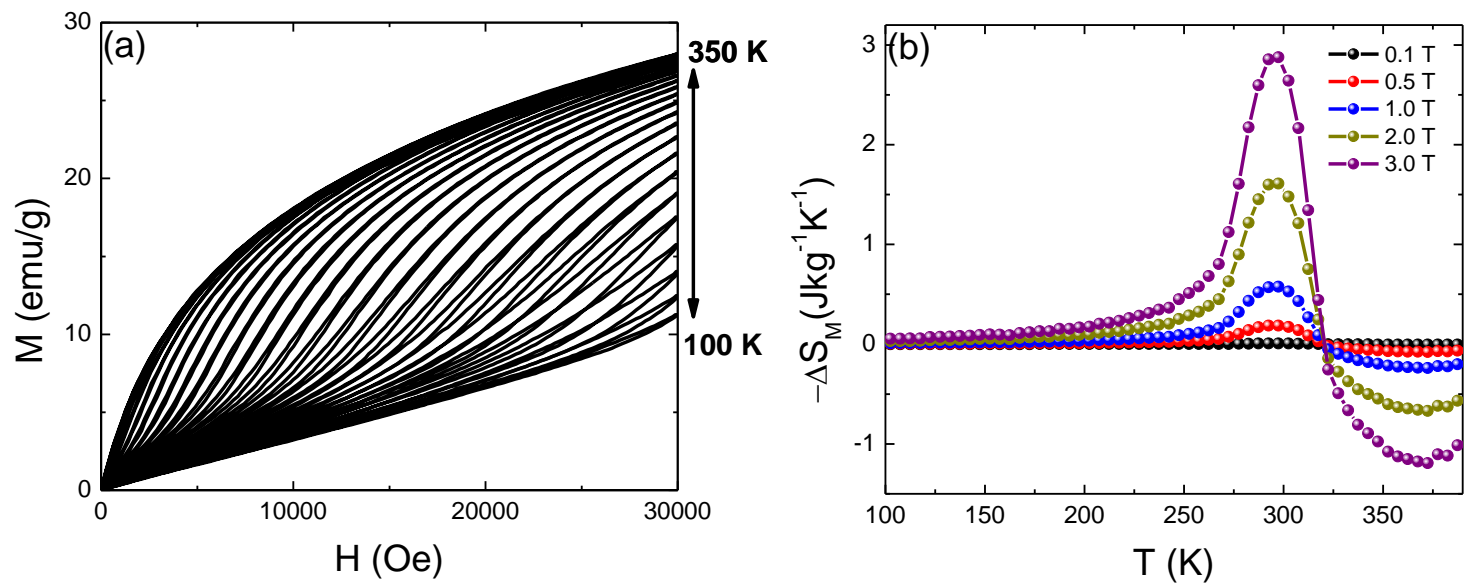

Figure 3. (a) Isothermal magnetization curves $(\mathrm{M}-\mathrm{H})$ measured at temperatures around the magnetostructural transition of $\mathrm{Mn}_{1.25} \mathrm{Fe}_{1.75} \mathrm{Ga}$ ribbons. (b) Temperature dependence of the change in magnetic entropy of $\mathrm{Mn}_{1.25} \mathrm{Fe}_{1.75} \mathrm{Ga}$ ribbons measured with a field of $3 \mathrm{~T}$.

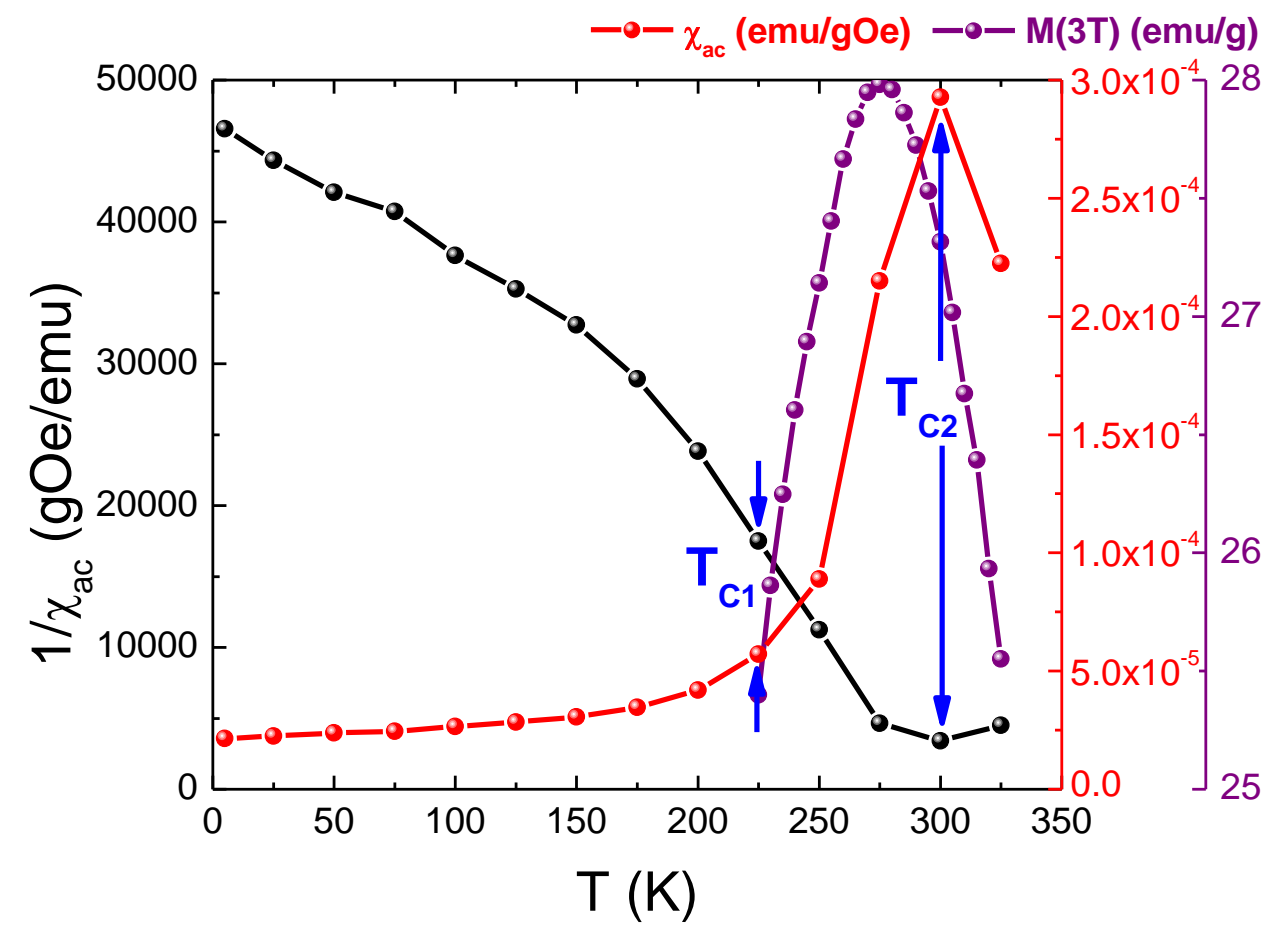

Figure 4. Dependence of A.C. succesptibility $\left(\chi_{\mathrm{ac}}\right)$ on temperature at a field and frequency of 100 Oe and $100 \mathrm{~Hz}$, respectively; also the temperature dependence of $\mathrm{M}$ at $3 \mathrm{~T}$ is shown. 

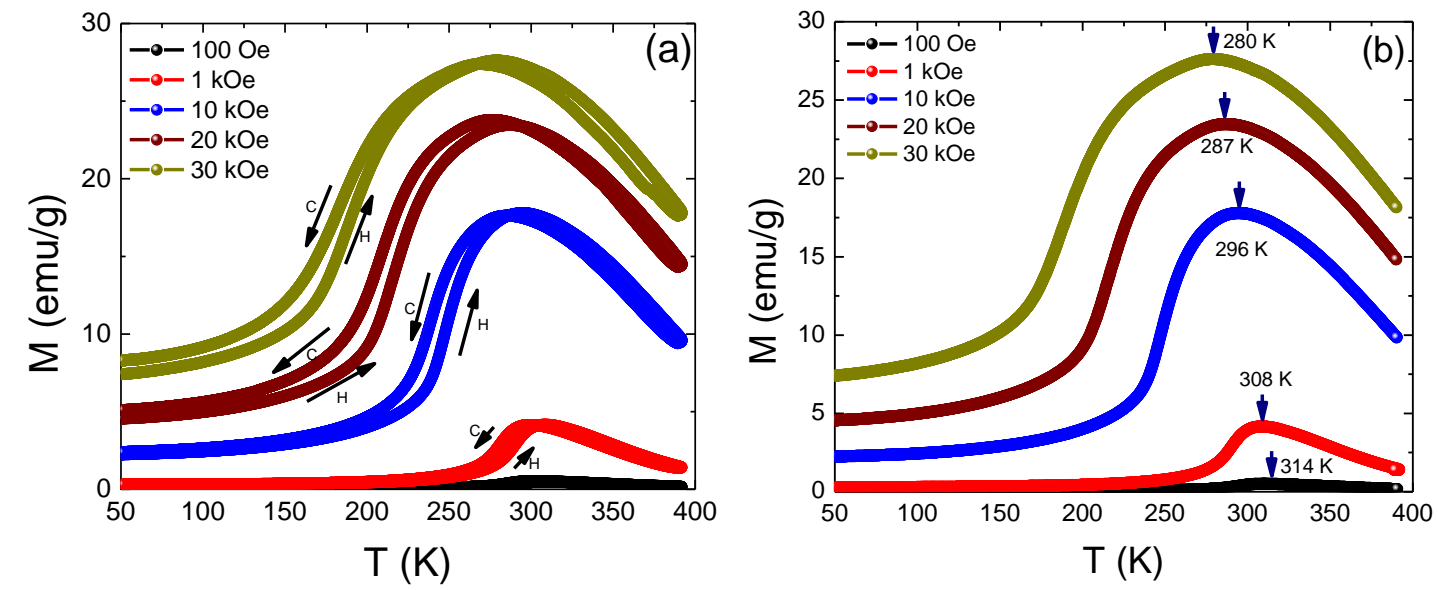

Figure 5. (a) M-T curves for $\mathrm{Mn}_{1.25} \mathrm{Fe}_{1.75} \mathrm{Ga}$ at different applied fields for heating and cooling cycles. (b) M-T heating curves show the effect of the applied fields on the transition temperatures.

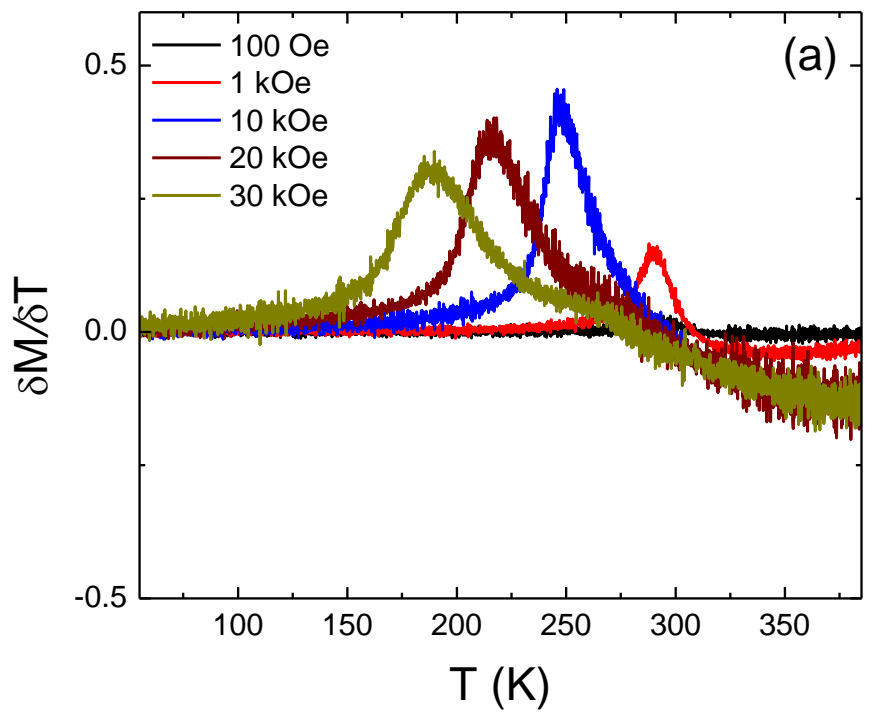

(b)

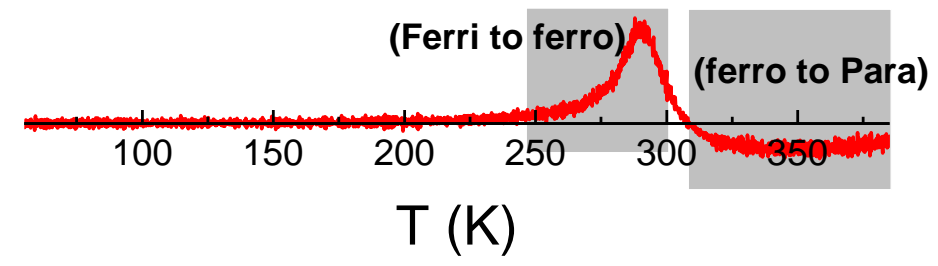




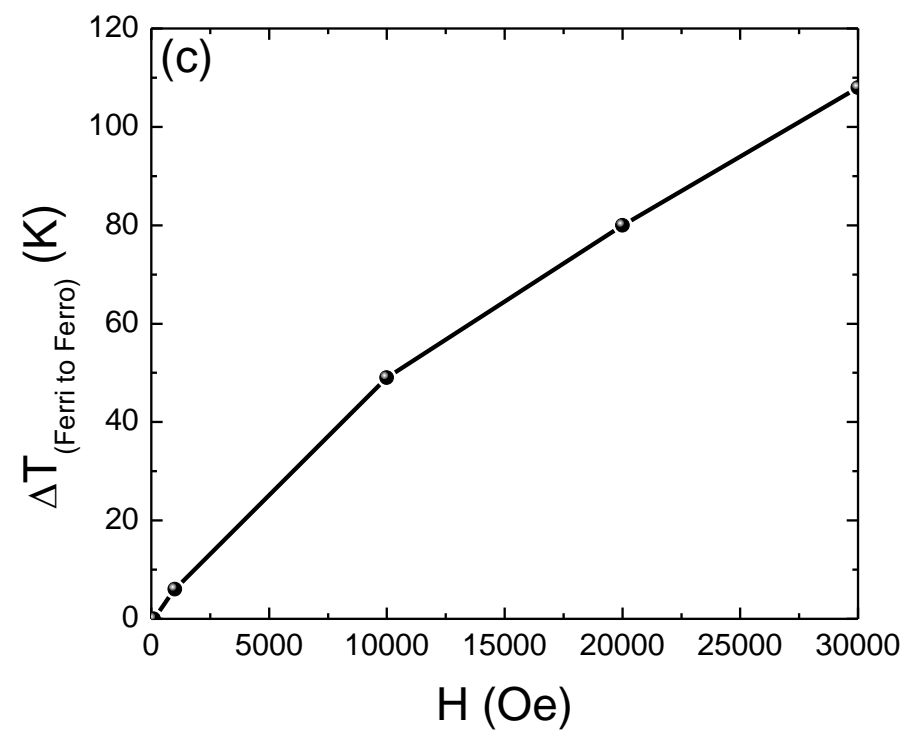

Figure. 6. (a) $\delta \mathrm{M} / \delta \mathrm{T}$ curves in $\mathrm{Mn}_{1.25} \mathrm{Fe}_{1.75} \mathrm{Ga}$ for different applied fields. The data were derived from the isothermal loops in Fig. 5. (b). (b) $\delta \mathrm{M} / \delta \mathrm{T}$ curve at 1000 Oe for understanding the state transitions in $\mathrm{Mn}_{1.25} \mathrm{Fe}_{1.75} \mathrm{Ga}$. (c) The shift of the ferri- to ferromagnetic transformation temperature dependence on the applied magnetic field. 